УДК 504.054

\title{
ЭКОЛОГИЧЕСКОЕ СОСТОЯНИЕ ПОЧВ ПРОМЫШЛЕННЫХ ТЕРРИТОРИЙ (НА ПРИМЕРЕ Г. БЕРЕЗНИКИ, ПЕРМСКИЙ КРАЙ): СРАВНЕНИЕ ОТЕЧЕСТВЕННЫХ И ЗАРУБЕЖНЫХ МЕТОДОВ ОЦЕНКИ
}

\author{
Ушакова Евгения Сергеевна 1 , \\ ushakova.evgeniya@gmail.com
}

\author{
Караваева Татьяна Ивановна ${ }^{1}$, \\ jewel_@list.ru
}

\author{
Белкин Павел Андреевич1, \\ pashabelkin@mail.ru
}
1 Пермский государственный национальный исследовательский университет, Россия, 614990, г. Пермь, ул. Генкеля, 4.

\begin{abstract}
Актуальность. Интенсивное антропогенное воздействие на окружающую среду, особенно в пределах промьшленных территорий, способствует деградации почвенного профиля и аккумуляции технофильных химических элементов в почвенном покрове. Увеличение загрязнения городских почв тяжельми металлами в связи с интенсивной промышленной нагрузкой является серьезной экологической проблемой. Несмотря на повышенный интерес к экологическому состоянию почв промышленных территорий, существующая в настоящее время в Российской Федерации система нормирования недостаточно разработана и не позволяет дать точную характеристику загрязнения.

Цель: определение уровня загрязнения тяжельми металлами почв в пределах промышленной зоны урбанизированной территории; сравнение отечественных и зарубежных методов оценки загрязненности почв и обоснование необходимости актуализации нормативно-технической документации.

Методы. Содержание тяжелых металлов в почвах определено масс-спектральным методом на базе сектора наноминералогии «Центра коллективного пользования Пермского государственного национального исследовательского университета». Результаты и выводы. Рассмотрены отечественные и зарубежные методы оценки экологического состояния почв. Проведена оценка уровня загрязнения почв тяжелыми металлами и металлоидами в пределах промышленных территорий крупных химических предприятий Пермского края с использованием отечественных и зарубежных нормативов качества почв, суммарных показателей загрязнения и индекса потенциального экологического риска. Показана необходимость учета функционального назначения территорий при оценке загрязнения с помощью индивидуальных показателей. Получены аналогичные результаты оценки степени загрязнения почв при использовании отечественных, не регламентированных нормативнотехнической документацией, и зарубежных суммарных показателей. Сделан вывод о необходимости актуализации нормативных требований Российской Федерации с учетом отечественного и зарубежного опыта оценки загрязненности почв.
\end{abstract}

\section{Ключевые слова:}

Нормативы качества почв, тяжелые металлы, уровень загрязнения почв, промышленные территории, суммарный показатель загрязнения, индекс потенциального экологического риска.

\section{Введение}

Интенсивное антропогенное воздействие на окружающую среду, особенно в пределах промышленных территорий, способствует деградации почвенного профиля и аккумуляции технофильных химических элементов в почвенном покрове. Почва, аккумулируя поступающие загрязняющие вещества, неизбежно оказывает влияние на сопредельные среды, выступая источником вторичного загрязнения атмосферного воздуха, природных вод, биотического комплекса.

Согласно ежегодным докладам и проведенным исследованиям в почвах российских городов за последнюю четверть века зафиксированы повышенные концентрации $\mathrm{Hg}, \mathrm{Zn}, \mathrm{Sn}, \mathrm{Mn}$ в зонах промышленности и автотранспорта, при этом наблюдается увеличение контрастности техногенных геохимических аномалий $(\mathrm{Cu}, \mathrm{Mo}, \mathrm{As}, \mathrm{Co}$ и $\mathrm{Cd})$ рядом с промышленными предприятиями, автомобильными и железными дорогами. Очаги геохимической нагрузки часто обусловлены осаждением в почвенном субстрате остаточных ингредиентов-микропримесей, содержащихся в нефти: $\mathrm{V}, \mathrm{Ni}, \mathrm{Co}, \mathrm{Hg}, \mathrm{As}, \mathrm{Cd}$ и др. [1-4].
Увеличение загрязнения городских почв тяжелыми металлами в связи с интенсивной промышленной нагрузкой является серьезной экологической проблемой крупных промышленных центров (табл. 1).

Установлено, что в городских почвах по сравнению с фоновыми почвами увеличивается подвижность металлов. Многолетние наблюдения в зонах влияния крупных промышленных предприятий фиксируют динамику прироста загрязненности почв тяжелыми металлами, что приводит к необходимости создания расширенных санитарно-защитных зон вокруг промышленных предприятий $[7,8]$.

Несмотря на повышенный интерес к экологическому состоянию почв промышленных территорий при научных исследованиях и необходимость почвенных исследований, обусловленную градостроительными, природоохранными и санитарными нормами, при проектировании, строительстве и реконструкции объектов существующая в настоящее время в Российской Федерации система нормирования недостаточно разработана и не позволяет дать точную характеристику загряз- 
нения [11-21]. Исследователи отмечают отсутствие градации по функциональному назначению территорий [20]. В СанПиН 2.1.7.1287-03 «Санитарноэпидемиологические требования к качеству почвы» (п. 4.4) функциональное использование территории учитывается только при определении перечня загрязнителей, а оценка загрязненности и последующее определение возможности дальнейшего использования почв выполняются без учета характера землепользования. При оценке степени загрязнения не учитываются техногенные и природные, обусловленные литологогеохимическими особенностями территории, доли со- держания элементов; различия в токсичности загрязняющих веществ при определении суммарного показателя загрязнения; последствия совместного воздействия на человека различных химических элементов [12]. При оценке экологического состояния почв рекомендуется использовать дополнительные критерии: подвижность металлов, биодоступность, чувствительность почвенной биоты и растительности, а комплексную оценку загрязненности проводить с использованием интегрального оценочного балла, отражающего совокупное действие тяжелых металлов с учетом степени их опасности для окружающей среды [10].

Таблица 1. Концентрации элементов в почвах промышленных территорий

Table 1. Concentrations of elements in industrial areas soils

\begin{tabular}{|c|c|c|c|c|c|c|}
\hline $\begin{array}{c}\text { Элементы } \\
\text { Elements }\end{array}$ & $\begin{array}{c}\text { Острава, } \\
\text { Чехия [5] } \\
\text { Ostrava, } \\
\text { Czech Republic [5] }\end{array}$ & $\begin{array}{c}\text { Гебзе, Турция [6] } \\
\text { Gebze, Turkey [6] }\end{array}$ & $\begin{array}{c}\text { Красноярск, } \\
\text { Россия [7] } \\
\text { Krasnoyarsk, } \\
\text { Russia [7] }\end{array}$ & $\begin{array}{c}\text { Благовещенск, } \\
\text { Россия [8] } \\
\text { Blagoveshchensk, } \\
\text { Russia [8] }\end{array}$ & $\begin{array}{c}\text { Ростов-на-Дону, } \\
\text { Россия [9] } \\
\text { Rostov-on-Don, } \\
\text { Russia [9] }\end{array}$ & $\begin{array}{c}\text { Нижний Новгород, } \\
\text { Россия [10] } \\
\text { Nizhny Novgorod, } \\
\text { Russia [10] }\end{array}$ \\
\hline $\mathrm{Ni}$ & - & - & 5,94 & $6-62$ & $50-60$ & $4,9-42,8$ \\
\hline $\mathrm{Cu}$ & $13,88-90,66$ & $7,87-725$ & 4,0 & $10-72$ & $50-150$ & $7,1-62,1$ \\
\hline $\mathrm{As}$ & - & $1,5-65,60$ & 3,6 & - & $4,1-6,1$ & - \\
\hline $\mathrm{Hg}$ & $0,13-1,31$ & $9,00-2721$ & 2,0 & - & $0,012-0,04$ & - \\
\hline $\mathrm{Cd}$ & $0,06-1,18$ & $0,05-176$ & 2,76 & $0,06-7,80$ & $0,1-0,53$ & $0,05-0,28$ \\
\hline $\mathrm{Pb}$ & $17,03-174,24$ & $17,07-8469$ & 39,16 & $22,4-311$ & $20-60$ & $7,0-66,4$ \\
\hline $\mathrm{Zn}$ & $85,16-373,58$ & $29,50-10000$ & 32 & $32-739$ & $200-500$ & $41,5-239,5$ \\
\hline
\end{tabular}

В соответствии с санитарно-гигиеническим ГОСТом 17.4.1.02-83 к опасным химическим веществам, попадающим в почву из выбросов, сбросов, отходов, относятся мышьяк, кадмий, ртуть, селен, свинец, цинк, фтор, бенз(а)пирен - первого класса опасности; бор, кобальт, никель, молибден, медь, сурьма, хром второго класса; барий, ванадий, вольфрам, марганец, стронций, ацетофенон - третьего класса. При этом ПДК и ОДК приняты только для 14 из всех перечисленных веществ.

Зарубежные подходы к оценке загрязненности почв более разнообразны по сравнению с отечественными. Стандарты содержания загрязняющих веществ в почвах устанавливаются для территорий с различными видами хозяйственного использования: пахотные земли, постоянные пастбища, жилые районы, детские площадки, парки и зоны рекреации, промышленные и коммерческие зоны [18, 19, 22, 23]. Эти значения могут быть дифференцированы в зависимости от состава и рН почвы [17] и обоснованы для большего перечня химических элементов [14].

Совершенно очевидным представляется необходимость актуализации нормативно-технической документации, регламентирующей оценку загрязненности почв, с учетом отечественного и зарубежного опыта.

Целью работы является сравнение отечественных и зарубежных методов оценки загрязненности почв и обоснование необходимости актуализации нормативно-технической документации.

В задачи исследований входила оценка состояния почв промышленных территорий в пределах санитарно-защитных зон двух крупных химических предприятий Пермского края и анализ результатов оценки при использовании отечественных и зарубежных методов.

\section{Территория исследования}

Город Березники расположен в северной части Пермского края и является крупным промышленным центром. Объектом исследования являются почвы промышленных территорий г. Березники (рис. 1). Промышленное освоение данной территории началось с 1883 г. на базе соляных промыслов при Березниковском содовом заводе. Промышленная зона располагается в левобережной части бассейна р. Камы. В настоящее время в пределах промзоны города расположены крупные предприятия: филиал «Азот» АО «ОХК «Уралхим», АО «Березниковский содовый завод», Березниковская ТЭЦ, ОАО «Сода-Хлорат», городские очистные сооружения. На всем протяжении промзоны присутствует промканал, в который осуществляется выпуск сточных вод промышленных предприятий.

Территория пересечена сетью автомобильных и железных дорог, необходимых для функционирования предприятий, практически вся площадь спланирована и покрыта твердой водонепроницаемой поверхностью (промышленная зона, асфальтированные дороги и проезды, производственные здания и территории).

Территория исследований испытывает значительную техногенную нагрузку со стороны промышленных предприятий. Установлено, что в 2018 г. основной вклад в суммарные выбросы загрязняющих веществ от стационарных источников вносили 10 предприятий Пермского края из них на территории Березниковского городского округа: филиал «Азот» АО ОХК «УРАЛХИМ» в г. Березники $(1,08 \%)$, АО «Березниковский содовый завод» $(2,7 \%)$ [24]. 


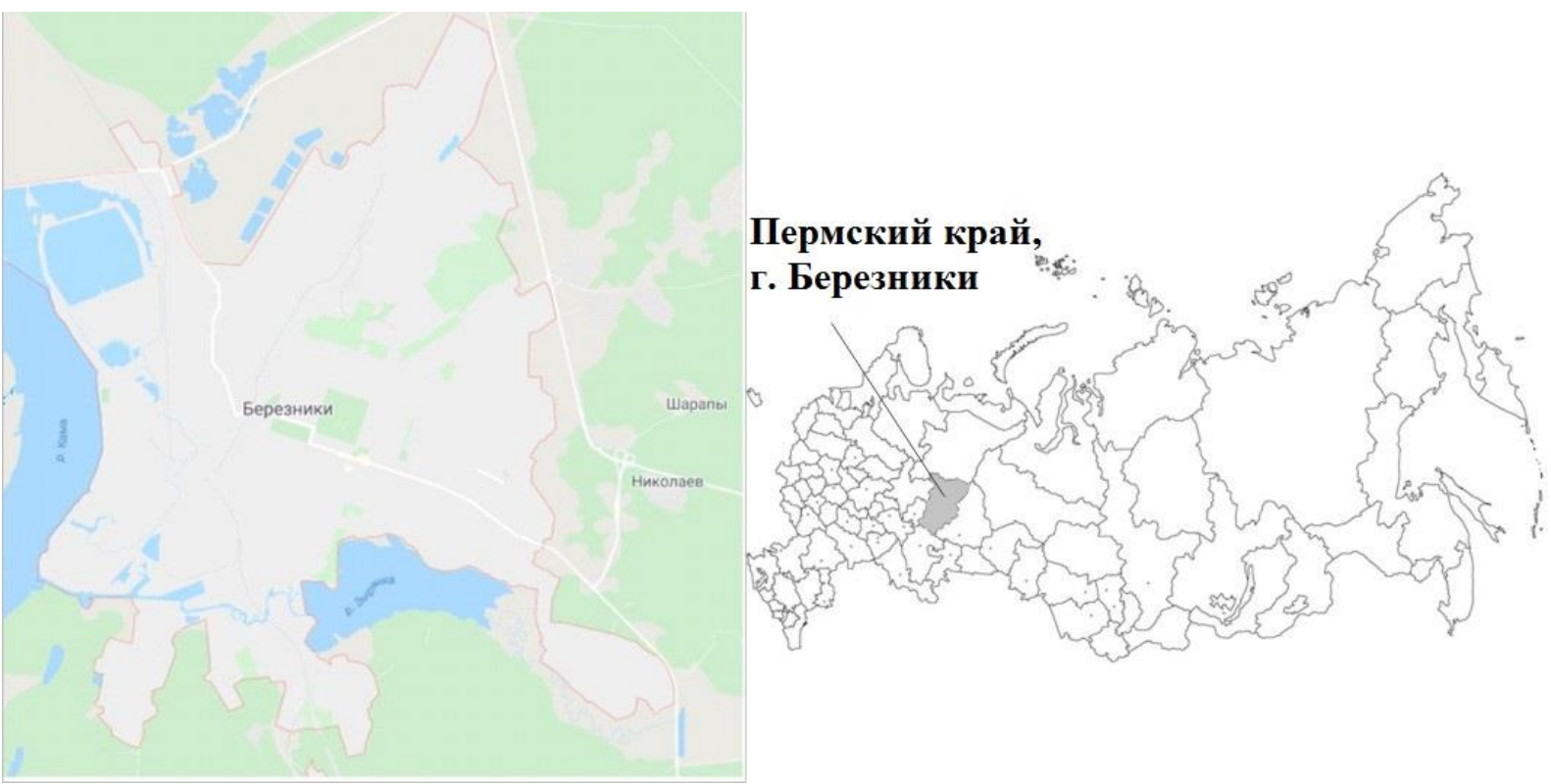

Рис. 1. Расположение района исследований на территории Российской Федерации

Fig. 1. Research area location on the territory of the Russian Federation

\section{Исходные данные}

Техногенные аномалии в почвенном покрове, связанные с выпадением загрязняющих веществ из атмосферы, образуются в самой верхней части почвенного профиля. Накопление тяжелых металлов техногенного происхождения в приповерхностном слое почвы объясняется тем, что основная их часть поступает в форме труднорастворимых или нерастворимых соединений, происходит их накопление в твердой фазе, что, прежде всего, выражается в увеличении их валового содержания [25].

Пространственное расположение и профильное строение почв являются совокупным результатом действия современных факторов почвообразования, в том числе антропогенного, а также наследия лито- и педогенеза. Структура почвенного покрова территории современных городов претерпела существенные изменения: появились новые почвы (урбостратоземы), техногенные поверхностные образования (в том числе целенаправленно созданные), которые в той или иной степени выполняют функции почв. Они зачастую не связаны между собой длительными почвенно-геохимическими процессами, ведущим фактором их образования является характер антропогенного воздействия. Почвенный покров характеризуется частой сменой почв и техногенных поверхностных образований и высокой степенью их контрастности. В силу высокой горизонтальной и вертикальной неоднородности почвенного покрова в основу представлений об его организации положено понятие урбопедокомплексов - комбинации почв и техногенных поверхностных образований на одинаковых почвообразующих породах в пределах определенной функциональной зоны [25]. На исследованной территории почвы представлены урбостратоземами супесчаного и песчаного состава, имеют выраженные признаки деградации: почвенный покров уплотнен, полноценная субстанция отсутствует, присутствуют мелкие камни, осколки стекла.

Учитывая преимущественную аккумуляцию загрязняющих веществ в приповерхностном слое, отбор проб почв осуществлялся с глубины 0-20 см методом комплексной пробы на реперных участках (РУ) в пределах промышленной и санитарно-защитной $30 \mathrm{H}$ промышленных предприятий г. Березники в соответствии с ГОСТ 17.4.4.02-84 «Охрана природы. Почвы. Методы отбора и подготовки проб для химического, бактериологического, гельминтологического анализа». Для оценки загрязненности почв принят перечень тяжелых металлов и металлоидов, регламентированный СанПиН 2.1.7.1287-03 в качестве стандартного: свинец, кадмий, цинк, медь, никель, мышьяк, ртуть.

Лабораторные исследования проводились на базе сектора наноминералогии «Центра коллективного пользования Пермского государственного национального исследовательского университета». Содержание микроэлементов в пробах почв определяли масс-спектральным методом на приборе BRUKER AURORA M90 ICP-MS. Разложение образцов почв проводили путем кислотного вскрытия в открытой системе. Для анализа использовали навески образцов массой 0,1 г. Вместе с анализируемыми образцами проводили разложение контрольных образцов (холостых проб) и одного стандартного образца. Для проверки правильности анализа образца использовали стандартные образцы Института Геохимии СО РАН (Иркутск): химического состава донного ила озера Байкал БИЛ-1 (ГСО 7126-94), карбонатно-силикатные рыхлые отложения СГХМ-1,2,3,4 (ГСО 3483-86, 3484-86, 3485-86, 3486-86), горные породы трапп СТ-2а (ГСО 8671-2005), габбро эссекситовое СГД-2а (ГСО 8670-2005).

Расположение реперных участков опробования обусловлено границами промышленной зоны города. Количество реперных участков составило 10. В каче- 
стве фоновой была выбрана территория, удаленная от зоны влияния крупных промышленных предприятий, покрытая условно-естественной растительностью. Почвенный покров представлен аллювиальными почвами со щелочной реакцией среды, легкого механического состава, соответствующего составу оцениваемых почв. Фоновое содержание элементов получено усреднением значений четырех фоновых проб.

\section{Существующие методические подходь} к оценке загрязненности почв

Эффективная оценка загрязнения почв тяжелыми металлами заключается в выборе подходящих компонентов загрязнения и методов оценки с целью выявления реальной геохимической обстановки на исследуемой территории. С помощью комплексирования различных методов оценки можно оценить степень накопления тяжелых металлов в почвах, а также уро- вень загрязнения. На сегодняшний день известно более 25 зарубежных и российских методов оценки загрязнённости почв [26-35]. Часто используемые индексы можно разделить на две группы: индивидуальные и общие комплексные (рис. 2). С помощью индексов загрязнения можно оценить состояние качества почвы с указанием класса опасности или уровня загрязнения. При комплексировании различных методов оценки необходимо учитывать слабые и сильные стороны каждого метода.

Согласно опубликованным данным, зарубежные авторы предпочитают использовать индекс геоаккумуляции (Igeo), коэффициент обогащения (EF), поскольку эти показатели считаются самыми полезными и универсальными [31, 36-47]. Данные показатели позволяют оценить загрязнение почв отдельным элементом с учетом его фонового значения.

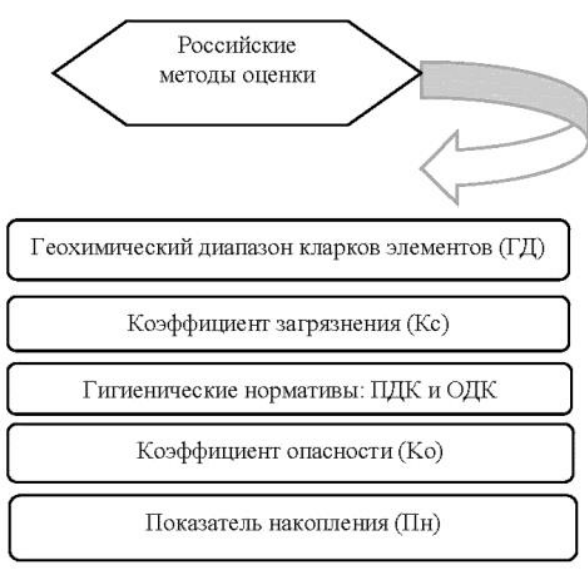

Коэффициент загрязнения (СF)

Общие комплексные индексы

Индекс экологического фактора риска $\left(\mathrm{E}_{\mathrm{r}}^{\mathrm{i}}\right)$

Индекс потенщиального экологического риска (RI)

Pис. 2. Зарубежные и российские методы оченки загрязненности поче

Fig. 2. Foreign and Russian methods for assessing soil contamination 
Многоэлементные или комплексные индексы загрязнения используют в случае недостаточной оценки одноэлементными индексами. Наиболее распространенными и широко используемыми являются уровень загрязнения $(\mathrm{Cd})$, индекс загрязнения (PI) и модифицированный индекс загрязнения (MPI) и т. д. Для оценки экологического риска эффективно применяют следующие показатели: индекс потенциального экологического риска (RI), средний коэффициент ERM (MERMQ), индекс степени загрязнения (CSI).

Российскими аналогами зарубежных индивидуальных или одноэлементных индексов являются коэффициент концентрации, кларк концентрации, коэффициент опасности. Данные показатели используют с учетом фонового значения, кларка или ПДК элемента в почве. При оценке суммарного загрязнения в России чаще всего используют суммарный показатель Саета Zc [48]. Кроме того, имеются различные вариации суммарного показателя: экологический показатель суммарного загрязнения, учитывающий разную токсичность тяжелых элементов - Zст, учитывающий средние геометрические коэффициенты концентрации элементов - Zc(г) и т. д.

Помимо одноэлементных индексов загрязнения используют сравнение содержания элементов с ПДК по установленным гигиеническим нормативам для территории РФ и зарубежных стран.

Существующие российские нормативные требования распространяются на почвы сельскохозяйственных угодий, населенных мест и зон санитарной охраны источников водоснабжения, территорий курортных зон. Для почв территорий промышленных предприятий нормативные критерии оценки отсутствуют.

Канадские нормативы качества почв (Soil Quality Guidelines, SQG), введенные в 1991 г. и периодически обновляемые, сейчас определены для валового содержания химических элементов в почвах для четырех функциональных зон (табл. 2) и направлены на защиту здоровья человека, наземных организмов и почвенных процессов от негативных последствий $[14,15,36]$.

В основу немецкого нормирования качества почв положены триггерные и предостерегающие значения, которые разработаны с учетом риска негативных воздействий для человека при кожных контактах с почвой и др. В случае превышения триггерных значений, дифференцированных для детских площадок, сельскохозяйственных, селитебных, парковых и индустриальных территорий, организуется мониторинг сельскохозяйственных угодий с дальнейшей оценкой опасности загрязнения (табл. 2) [14, 15, 37].

Система нормирования качества почв Австралии и Новой Зеландии оформилась в 1992 г., когда была принята инструкция по оценке и управлению загрязненных территорий, основанная на экологических подходах отдельных муниципалитетов двух стран [38]. В Австралии разработаны экосистемнооценочные уровни для четырех функциональных зон (Ecological Investigation Levels, EIL) на основе фитотоксикологических экспериментов и фоновой почвенной съемки в четырех столицах для урбанизированных территорий и оценочные уровни для здоровья человека (Health InvestigationLevels, HIL), зависящие от типа землепользования (табл. 2) [14, 15, 39].

Нормирование содержания химических элементов в почвах ЮАР базируется на канадских подходах. Нормативы (Soil Screening Values) (табл. 2) получены по минимальному уровню среди трех расчетов в системе источник-путь-получатель. В настоящее время существуют нормативы для валового содержания химических элементов в почвах четырех функциональных зон, в том числе для коммерческих и индустриальных территорий $[14,15,40]$. Например, стандарты качества почвенной среды в Китае требуют пересмотра в связи с нехваткой научных исследований, связанных с концентрацией тяжелых металлов в почвенном покрове и их экологическими последствиями для здоровья человека $[41,43]$.

Оценка загрязненности почв исследуемой территории проведена с использованием российских гигиенических нормативов (ПДК и ОДК), а также нормативов, установленных для почв индустриальных и коммерческих территорий Германии, Канады, Австралии и ЮАР по стандартным семи элементам.

Таблица 2. Нормативы содержания элементов в почвах

Table 2. Norms of elements content in soils

\begin{tabular}{|c|c|c|c|c|c|c|}
\hline \multirow{3}{*}{$\begin{array}{l}\text { Элементы } \\
\text { Elements }\end{array}$} & \multirow{2}{*}{\multicolumn{2}{|c|}{$\begin{array}{c}\text { Содержание, мг/кг } \\
\text { Content, mg/kg } \\
\text { Pocсия/Russia }\end{array}$}} & \multicolumn{4}{|c|}{$\begin{array}{c}\text { Содержание, мг/кг (для промышленных и коммерческих территорий) } \\
\text { Content, mg/kg (for industrial and commercial areas) }\end{array}$} \\
\hline & & & \multirow[b]{2}{*}{$\begin{array}{c}\text { Германия [37] } \\
\text { Germany [37] }\end{array}$} & \multirow[b]{2}{*}{$\begin{array}{l}\text { Канада [36] } \\
\text { Canada [36] }\end{array}$} & \multirow[b]{2}{*}{$\begin{array}{c}\text { Австралия [39] } \\
\text { Australia [39] }\end{array}$} & \multirow[b]{2}{*}{$\begin{array}{c}\text { ЮAP [40] } \\
\text { South Africa [40] }\end{array}$} \\
\hline & $\begin{array}{l}\text { ПДК } \\
\text { МРС }^{*}\end{array}$ & $\begin{array}{l}\text { ОДК }^{* *} \\
\text { АРC }^{* *}\end{array}$ & & & & \\
\hline Мышьяк/Arsenic & 2 & $2-10$ & 140 & 12 & 500 & 150 \\
\hline Кадмий/Cadmium & $-^{* * * 4}$ & $0,5-2,0$ & 60 & 22 & 100 & 260 \\
\hline Свинец/Lead & 32 & $32-130$ & 2000 & 600 & 1500 & 1900 \\
\hline Никель/Nickel & - & $20-80$ & 900 & 89 & 3000 & 10000 \\
\hline Ртуть/Mercury & 2,1 & - & 80 & 50 & 75 & 6,5 \\
\hline Медь/Copper & - & $33-132$ & - & 91 & 5000 & 19000 \\
\hline Цинк/Zinc & - & $55-220$ & - & 410 & 35000 & 150000 \\
\hline
\end{tabular}

*Предельно допустимые концентрачии (ПДК) химических веществ в почве; ${ }^{* *}$ Ориентировочно допустимые концеетрации (ОДК) химических вещзеств в песчаных и суглинистых почвах; "*** Прочерк означает, что официальный норматив не разработан.

*Maximum Permissible Concentrations (MPC) of chemicals in soil; **Approximate Permissible Concentrations (APC) of chemicals in sandy and loamy soils; ${ }^{* * *}$ A dash means that no official standard has been developed. 
Оценка суммарного загрязнения произведена по показателям $Z_{c}, Z_{c m}$ с использованием коэффициента токсичности элемента и $R I$ (данный показатель у разных авторов можно встретить с другой аббревиатурой, например, PERI) [31, 46, 47].

Суммарный показатель химического загрязнения $Z_{c}$ характеризует степень химического загрязнения почв обследуемых территорий вредными веществами различных классов опасности и определяется как сумма коэффициентов концентрации отдельных компонентов:

$$
Z_{c}=K_{c 1}+. . K_{c i}+\ldots K_{c n}-(n-1),
$$

где $n$ - число определяемых компонентов; $K_{c i}-$ коэффициент концентрации $i$-го загрязняющего компонента, равный кратности превышения содержания данного компонента над фоновым значением.

Степень токсичности (и опасности) тяжелых элементов различна. Очевидно, что при одинаковых значениях концентрации суммарное загрязнение будет опаснее, если в почве концентрируются самые токсичные элементы первой группы. Чтобы внести соответствующие поправки на токсичность, следует в формуле при определении суммарного показателя химического загрязнения разным элементам придать разный вес, отвечающий их группе опасности [11].

Экологический показатель суммарного загрязнения $\left(Z_{c m}\right)$, рассчитывается с учетом степени токсичности элементов, а также коэффициентов концентрации $\left(K_{k i}\right)$ :

$$
K_{k i}=C_{i} / C_{i \phi}
$$

где $C_{i \phi}$ и $C_{i}$ - фоновое и фактическое содержание $i$-го элемента в почве;

$$
Z_{c m}=\sum_{i=0}^{n}\left(K_{k i} \times K_{t i}-(n-1)\right),
$$

где $K_{t i}-$ коэффициент токсичности $i$-го элемента. Для элементов первого класса опасности коэффициент составляет 1,5 (As, $\mathrm{Cd}, \mathrm{Hg}, \mathrm{Se}, \mathrm{Pb}, \mathrm{Zn}$ ), для элементов второго класса опасности - $1,0(\mathrm{Co}, \mathrm{Ni}, \mathrm{Mo}, \mathrm{Cu}, \mathrm{Sb}$, $\mathrm{Cr})$, для элементов третьего класса опасности - 0,5 (Ba, V, W, Mn, Sr).

Критические значения, позволяющие охарактеризовать суммарное загрязнение по степени опасности, для показателей $Z_{c}$ и $Z_{c m}$ едины: при $Z_{c}\left(Z_{c m}\right)<16$ загрязнение считается неопасным; при $16<Z_{c}\left(Z_{c m}\right)<32-$ умеренно опасным; при $32<Z_{c}\left(Z_{c m}\right)<128$ - опасным; при $Z_{c}\left(Z_{c m}\right)>128$ - чрезвычайно опасным.

Метод оценки потенциального риска загрязнения тяжелыми металлами $(R I)$ разработан шведским ученым Л. Хакансоном. При оценке данным методом учитывается не только содержание тяжелых металлов в почве, но и возможные негативные экотоксикологические последствия загрязнения $[44,45]$. В соответствии с этим методом, потенциальный экологический риск рассчитывается с помощью коэффициента $E_{r}^{i}$ :

$$
\begin{gathered}
C_{f}^{i}=\frac{C_{s}^{i}}{C_{n}^{i},} \\
E_{r}^{i}=T_{r}^{i} \times C_{f}^{i}, \\
R I=\sum_{i=1}^{n} E_{r}^{i},
\end{gathered}
$$

$C_{f}^{i}$ является коэффициентом загрязнения (аналог российского коэффициента концентрации $\left.K_{c}\right) ; C_{s}^{i}$ и $C_{n}^{i}-$ фактическое и фоновое содержание $i$-го элемента в почве.

Коэффициент токсичности $T_{r}^{i}$ представлен в табл. 3.

Таблица 3. Коэффициент токсичности тяжелых металлов [26, 45]

Table 3. Toxicity factor of heavy metals

\begin{tabular}{|c|c|c|c|c|c|c|c|c|}
\hline Элемент/Element & $\mathrm{As}$ & $\mathrm{Cd}$ & $\mathrm{Cr}$ & $\mathrm{Cu}$ & $\mathrm{Pb}$ & $\mathrm{Ni}$ & $\mathrm{Zn}$ & $\mathrm{Hg}$ \\
\hline 3начения/ & 10 & 30 & 2 & 5 & 5 & 5 & & 4 \\
\hline
\end{tabular}

\begin{tabular}{|l|c|c|c|c|c|c|c|c|}
\hline Значения/Values & 10 & 30 & 2 & 5 & 5 & 5 & 1 & 40
\end{tabular}

Согласно Хакансону [44], для значений $E_{r}^{i}$ и $R I$ предложены следующие категории экологического риска: $E_{r}^{i}<40$ - низкий экологический риск; $40<E_{r}^{i} \leq 80$ - умеренный экологический риск; $80<E_{r}^{i} \leq 160$ - значительный экологический риск; $160<E_{r}^{i} \leq 320$ - высокий экологический риск; $E_{r}^{i}>320$ - чрезмерно высокий экологический риск; $R I<150$ - низкий экологический риск; $150<R I<300$ - умеренный экологический риск; $300<R I<600$ - высокий экологический риск; $R I \geq 600$ экстремально высокий экологический риск.

\section{Результаты и обсуждение}

Результаты экологической оценки почвенного покрова промышленной территории г. Березники на основе отечественных и зарубежных методов представлены в табл. 4-6 и на рис. 2. Водная вытяжка характеризуется разнофациальным составом: гидрокарбонатно-кальциевый и натриевый, сульфатно-кальциевый, нитратно-кальциевый и нитратно-натриевый. Почвы в интервале опробования РУ1-РУ4 представлены супесью с рНсол от 5,8 до 7,1; в интервале опробования РУ5-РУ 10 - песками с рНсол от 6,6 до 8,0.

Таблица 4. Содержание валовых форм тяжельх метал-

\begin{tabular}{|c|c|c|c|c|}
\hline \multirow{2}{*}{$\begin{array}{l}\text { Элемент } \\
\text { Element }\end{array}$} & \multicolumn{3}{|c|}{$\begin{array}{c}\text { Содержание, мг/кг }(n=10) \\
\text { Content, } \mathrm{mg} / \mathrm{kg}(n=10)\end{array}$} & \multirow{2}{*}{$\begin{array}{c}\text { Фоновое содержа- } \\
\text { ние, мг/кг }(n=4) \\
\text { Background content, } \\
\text { mg/kg }(n=4)\end{array}$} \\
\hline & $\begin{array}{l}\text { Среднее } \\
\text { Average }\end{array}$ & $\begin{array}{l}\text { Минимум } \\
\text { Minimum }\end{array}$ & $\begin{array}{l}\text { Максимум } \\
\text { Maximum }\end{array}$ & \\
\hline $\mathrm{Ni}$ & 18,7 & 5,7 & 29,0 & 5,7 \\
\hline $\mathrm{Cu}$ & 37,66 & 11,4 & 60,3 & 11,6 \\
\hline As & 3,77 & 1,3 & 9,2 & 1,3 \\
\hline $\mathrm{Hg}$ & 1,91 & 0,59 & 4,67 & 4,67 \\
\hline $\mathrm{Cd}$ & 0,31 & 0,08 & 0,54 & 0,08 \\
\hline $\mathrm{Pb}$ & 8,25 & 6,9 & 9,6 & 9,6 \\
\hline $\mathrm{Zn}$ & 96,84 & 27,0 & 140,5 & 27,0 \\
\hline
\end{tabular}
лов и металлоидов в почвенном покрове промымиленной территории г. Березники, мг/ка

Table 4. Contents of gross forms of heavy metals and metalloids in the soil cover of the industrial territory of Berezniki, $\mathrm{mg} / \mathrm{kg}$

При оценке микроэлементного состава анализировалось валовое содержание элементов с учетом кислотности среды и литологического состава субстрата. Превышение относительно ПДК (ОДК) выявлено для всех участков опробования по мышьяку (за исключением РУ1), отмечены разовые превышения по ртути, цинку, никелю и меди. Кратность превышений над ПДК (ОДК) по содержанию мышьяка достигает 4,6 раза; по ртути - 2,2; по цинку - 2,5; по никелю - 1,4; 
по меди - 1,8 раза. Согласно СанПиН 2.1.7.1283-03 установлена «опасная» категория загрязнения исследуемых почв неорганическими соединениями I и II классов опасности. Почвы на всей территории имеют ограничения по использованию при проведении земляных работ и требуют перекрытия слоем чистого грунта. Такие мероприятия в условиях постоянной геохимической нагрузки на промышленных территориях, которые даже в самой отдаленной перспективе не будут использоваться в сельском хозяйстве, не всегда целесообразны и, как правило, приводят к увеличению объемов загрязненных почв на данных территориях.

Используя для оценки загрязнения системы нормирования качества почв Германии, Канады, Австралии, ЮАР, учитывающие функциональное назначение территории (коммерческие и индустриальные), получаем иную картину, свидетельствующую об отсутствии превышений ПДК (критических значений). Таким образом, экологическое состояние почв полностью соответствует требованиям, предъявляемым для промышленных и коммерческих территорий. При этом канадские нормативы качества почв, по сравнению с нормативами других стран, являются самыми жесткими. Недостатком нормирования качества почв в Германии является минимальный перечень химических элементов, имеющий триггерный уровень содержания, - шесть элементов. Системы нормирования Австралии и ЮАР отличаются чрезмерно высокими уровнями допустимых значений, используемых для оценки почв. Такие значения содержания элементов характерны для техногенно нарушенных территорий с повышенным экологическим риском.

Канадские нормативы содержания химических элементов в почвах функциональных зон разработаны для более широкого перечня элементов и, с учетом схожих природно-климатических условий, являются наиболее подходящими для территории России.

Таблица 5. Уровень загрязнения почвенного покрова относительно нормативных значений

Table 5. Pollution level of soil cover in relation to normative values

\begin{tabular}{|c|c|c|c|c|c|c|c|}
\hline Statistic & $\mathrm{As}$ & $\mathrm{Cd}$ & $\mathrm{Hg}$ & $\mathrm{Pb}$ & $\mathrm{Zn}$ & $\mathrm{Ni}$ & $\mathrm{Cu}$ \\
\hline \multicolumn{8}{|c|}{ Poссия/Russia } \\
\hline Min & 0,650 & 0,160 & 0,281 & 0,216 & 0,491 & 0,285 & 0,345 \\
\hline Max & 4,600 & 1,080 & 2,224 & 0,300 & 2,555 & 1,450 & 1,827 \\
\hline Median & 1,675 & 0,630 & 0,750 & 0,258 & 1,895 & 1,010 & 1,148 \\
\hline \multicolumn{8}{|c|}{ Германия/Germany } \\
\hline Min & 0,009 & 0,001 & 0,007 & 0,003 & - & 0,006 & - \\
\hline Max & 0,066 & 0,009 & 0,058 & 0,005 & - & 0,032 & - \\
\hline Median & 0,024 & 0,005 & 0,020 & 0,004 & - & 0,022 & - \\
\hline \multicolumn{8}{|c|}{ Канада//Canada } \\
\hline Min & 0,108 & 0,004 & 0,012 & 0,012 & 0,066 & 0,064 & 0,125 \\
\hline Max & 0,767 & 0,025 & 0,093 & 0,016 & 0,343 & 0,326 & 0,663 \\
\hline Median & 0,279 & 0,014 & 0,032 & 0,014 & 0,254 & 0,227 & 0,416 \\
\hline \multicolumn{8}{|c|}{ Aвстралия/Australia } \\
\hline Min & 0,003 & 0,001 & 0,008 & 0,005 & 0,001 & 0,002 & 0,002 \\
\hline Max & 0,018 & 0,005 & 0,062 & 0,006 & 0,004 & 0,010 & 0,012 \\
\hline Median & 0,007 & 0,003 & 0,021 & 0,006 & 0,003 & 0,007 & 0,008 \\
\hline \multicolumn{8}{|c|}{ OAP/South Africa } \\
\hline Min & 0,009 & 0,000 & 0,091 & 0,004 & 0,000 & 0,001 & 0,001 \\
\hline Max & 0,061 & 0,002 & 0,718 & 0,005 & 0,001 & 0,003 & 0,003 \\
\hline Median & 0,022 & 0,001 & 0,242 & 0,004 & 0,001 & 0,002 & 0,002 \\
\hline
\end{tabular}

Для оценки химического загрязнения почв использован суммарный показатель химического загрязнения $Z_{c}$ как индикатор неблагоприятного воздействия на здоровье населения, характеризующий степень загрязнения почв обследуемых территорий металлами I-III классов опасности и рассчитанный как сумма коэффициентов концентраций отдельных компонентов загрязнения. В качестве фоновых значений для расчета коэффициентов концентраций использованы значения содержания элементов в пробах почв супесчаного состава, отобранных на условно-фоновой территории без антропогенного влияния.

По результатам расчетов значения суммарного показателя $Z_{c}$ составили от 7 до 25 (при допустимом уровне 16). К категории загрязнения «допустимая» относятся участки РУ1 и РУ2 в южной части территории исследований, ближайшие к «фоновой» территории. Почвы остальных реперных участков характеризуются «умеренно опасной» категорией загрязнения.

По показателю $Z_{c m}$ к категории загрязнения «допустимая» относятся участки РУ1 и РУ2, к категории загрязнения «умеренно опасная» - участки РУ3 и РУ4, к категории загрязнения «опасная» - участки РУ5РУ10. Таким образом, оценка загрязненности по показателю $Z_{c m}$ позволила более детально охарактеризовать территорию, дифференцировав области загрязнения в зависимости от опасности каждого элемента.

Экологический показатель суммарного загрязнения $Z_{c m}$, рассчитанный с учетом поправочного коэффициента на токсичность, отличается от суммарного показателя $Z_{c}$ повышенным уровнем загрязнения в 1,7 раза.

Для сравнения результатов отечественных и зарубежных методов оценки загрязненности почв дополнительно к вышеприведенной оценке по показателю $Z_{c m}$ рассчитан индекс потенциального экологического риска $(R I)$. Результаты оценки потенциального экологического фактора риска $\left(E_{r}^{i}\right)$ и индекс потенциального экологического риска $(R I)$ представлены в табл. 6.

Порядок потенциального экологического фактора риска $\left(E_{r}^{i}\right)$ тяжелых металлов следующий $\mathrm{Cd}>\mathrm{Hg}>\mathrm{Ni}>\mathrm{As}>\mathrm{Cu}>\mathrm{Zn}>\mathrm{Pb}$. Значения экологического фактора риска по элементам изменяются от 2 до 324, что свидетельствует о категориях экологического риска от низкого до чрезмерно высокого. К низкой категории экологического риска относятся $\mathrm{As}, \mathrm{Zn}, \mathrm{Cu}$ и Ni. Наибольшая вариация значений наблюдается у $\mathrm{Cd}$ и $\mathrm{Hg}$, при этом у элементов категория экологического риска возрастает от умеренного до высокого. Средний коэффициент потенциального экологического риска $(R I) \mathrm{As}, \mathrm{Cd}, \mathrm{Hg}, \mathrm{Pb}, \mathrm{Zn}, \mathrm{Ni}, \mathrm{Cu}$ составляет 328 и свидетельствует в целом о высоком экологическом риске.

Значения $R I$ по всем участкам находятся в диапазоне от 138 до 457, что соответствует общему уровню экологического риска от «низкого» до «высокого». Индекс потенциального экологического риска (RI) является аналогичным экологическому показателю суммарного загрязнения $Z_{c m}$, поскольку при расчете данных показателей учитывается токсичность эле- 
ментов. Выделенные территории по уровню экологического риска $(R I)$ в целом соответствуют участкам с установленными категориями загрязнения. Исключе- ние составляет участок РУ1, для которого уровень экологического риска (по показателю $R I$ ) выше установленной категории загрязнения (по показателю $Z_{c m}$ ).

Таблица 6. Оценка потенциального риска загрязнения тяжелыми металлами почв промышленной территории 2. Березники Пермского края

Table 6. Assessment of potential risk of heavy metals pollution in soils of the industrial territory of Berezniki, Perm region

\begin{tabular}{|c|c|c|c|c|c|c|c|c|c|}
\hline \multirow{2}{*}{$\begin{array}{c}\text { Py } \\
\text { Sampling site }\end{array}$} & \multicolumn{7}{|c|}{$\begin{array}{c}\text { Единый индекс экологического фактора риска }\left(E_{r}^{i}\right) \\
\text { Unified Environmental Risk Factor Index }\left(E_{r}^{i}\right)\end{array}$} & \multirow[t]{2}{*}{$R I$} & \multirow{2}{*}{$\begin{array}{l}\text { Градация риска } \\
\text { Risk gradation }\end{array}$} \\
\hline & As & $\mathrm{Cd}$ & $\mathrm{Hg}$ & $\mathrm{Pb}$ & $\mathrm{Zn}$ & $\mathrm{Ni}$ & $\mathrm{Cu}$ & & \\
\hline PY1 & 5,20 & 48,00 & 205,27 & 4,60 & 2,09 & 6,63 & 3,05 & 275 & Умеренный/Moderate \\
\hline Py2 & 16,00 & 78,00 & 25,93 & 4,46 & 3,88 & 7,21 & 3,00 & 138 & Низкий/Low \\
\hline PУ3 & 36,80 & 108,00 & 43,08 & 4,31 & 5,71 & 24,30 & 15,87 & 238 & Умеренный/Moderate \\
\hline PУ4 & 12,00 & 138,00 & 60,66 & 4,17 & 7,54 & 17,91 & 14,50 & 255 & Умеренный/Moderate \\
\hline Py5 & 12,40 & 174,00 & 77,80 & 4,03 & 9,37 & 20,35 & 13,13 & 311 & Высокий/High \\
\hline PУ 6 & 12,80 & 204,00 & 95,38 & 3,88 & 10,87 & 22,67 & 11,76 & 361 & Высокий/High \\
\hline Py7 & 13,20 & 234,00 & 112,97 & 3,74 & 10,06 & 25,12 & 10,39 & 409 & Высокий/High \\
\hline PУ8 & 13,60 & 264,00 & 130,11 & 3,60 & 9,26 & 27,44 & 9,03 & 457 & Высокий/High \\
\hline PУ9 & 14,00 & 294,00 & 40,00 & 3,45 & 8,46 & 32,09 & 9,55 & 402 & Высокий/High \\
\hline PУ10 & 14,80 & 324,00 & 49,67 & 3,31 & 7,66 & 33,72 & 8,82 & 442 & Высокий/High \\
\hline Среднеe/Average & 15,08 & 186,60 & 84,09 & 3,95 & 7,49 & 21,74 & 9,91 & 328,87 & Высокий/High \\
\hline
\end{tabular}
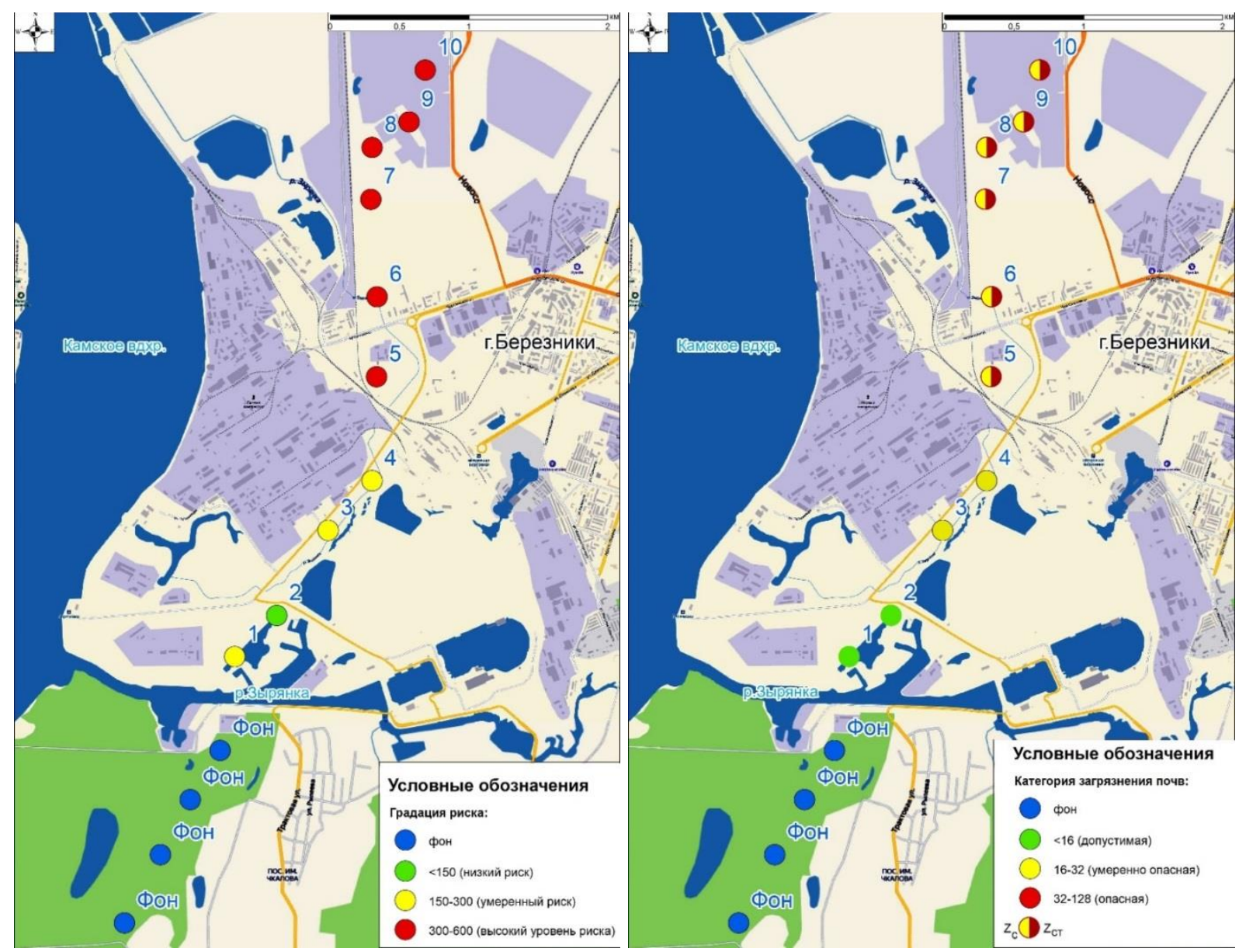

Pис. 3. Пространственное распределение (А) индекса потенциального экологического риска и (Б) суммарных показателей загрязнения на территории промышленной зоны Березниковского городского округа, Пермского края

Fig. 3. Spatial distribution (A) of potential ecological risk and (B) total pollution indices in the industrial zone of Berezniki urban district, Perm region

\section{Заключение}

Современная российская система нормирования в области оценки загрязненности почв объединяет две концепции: геохимическую и экологическую [11].
При геохимическом подходе критерием загрязнения является соотношение содержания элемента в загрязненной почве к его содержанию в «фоновой» почве. Наиболее часто используемым показателем при геохимическом методе оценки является суммар- 
ный показатель химического загрязнения, при расчете которого не учитывается различие в токсичности (и опасности) элементов. При одинаковых значениях концентрации суммарное загрязнение будет опаснее, если в почве концентрируются самые токсичные элементы первой группы. Соответствующие поправки на токсичность элементов учитываются в экологическом показателе суммарного загрязнения [12]. Аналогичный метод оценки применяют в зарубежных странах, определяя уровень экологического риска территории. Приведенные в статье результаты оценки территории по уровню потенциального экологического риска в целом соответствует выделенным участкам с различными категориями загрязнения по суммарному показателю загрязнения с учетом использования коэффициента токсичности.

При экологическом подходе валовое содержание элементов в почве оценивается относительно его предельно допустимой концентрации или ориентировочно допустимой концентрации. Принятые фиксированные величины предельно и ориентировочно допустимых концентраций не учитывают различия в функциональном назначении территорий в России. В отличие от

\section{СПИСОК ЛИТЕРАТУРЫ}

1. Касимов Н.С., Власов Д.В. Тяжелые металлы и металлоиды в почвах российских городов (по данным ежегодных докладов росгидромета) // Вестник Московского университета. Серия 5. География. - 2018. - № 3. - С. 14-22.

2. Власов Д.В., Касимов Н.С. Геохимические аномалии металлов и металлоидов в компонентах ландшафтов в восточной части Москвы: парагенезисы элементов и типология // Вестник Московского университета. Серия 5. География. - 2016. № 3. - С. 50-57.

3. Ворончихина Е.А., Ушакова Е.С. Геохимия ландшафтов. Пермь: Изд-во Перм. гос. нац. исслед. ун-т, 2012. - 139 с.

4. Корляков И.Д., Касимов Н.С., Кошелева Н.Е. Тяжелые металлы и металлоиды в почвенном покрове г. Улан-Удэ // Вестник Пермского национального исследовательского политехнического университета. Прикладная экология. Урбанистика. 2019. - № 3. - C. 120-137. DOI: 10.15593/2409-5125/2019.03.09

5. Potential ecological risk and human health risk assessment of heavy metal pollution in industrial affected soils by coal mining and metallurgy in Ostrava, Czech Republic / H. Doležalová Weissmannová, S. Mihočová, P. Chovanec, J. Pavlovský// International Journal of Environmental Research and Public Health. - 2019. 16 (22), 4495. URL: https://doi.org/10.3390/ijerph16224495 (дата обрашения 01.09.2020).

6. Yaylal1-Abanuz G. Heavy metal contamination of surface soil around Gebze industrial area, Turkey // Microchemical Journal. 2011. - V. 99. - P. 82-92. DOI: 10.1016/j.microc.2011.04.004

7. Горлушкина К.С., Бадмаева С.Э Содержание тяжелых металлов в почвах промышленных предприятий г. Красноярска // Вестник КрасГАУ. - 2018. - № 6. - С. 254-258.

8. Радомская В.И., Бородина Н.А. Оценка антропогенного загрязнения почвы урбанизированной территории на примере города Благовещенска // Геоэкология. Инженерная геология Гидрогеология, Геокриология. - 2019. - № 6. - С. 79-93. DOI https://doi.org/10.31857/S0869-78092019679-93

9. Шишкина Д.Ю. Тяжёлые металлы в почвах Ростова-наДону. - Ростов-на-Дону; Таганрог: Изд-во Южного федерального университета, 2017. - $98 \mathrm{c}$.

10. Дабахов М.В. Экологическая оценка техногенно загрязненных почв урбанизированных территорий и промышленных зон г. Нижнего Новгорода: автореф. дис. ... д-ра биол. наук. - М., 2012. -46 с

11. Водяницкий Ю.Н. Тяжелые металлы и металлоиды в почвах. - М ГНУ Почвенный институт им. В.В. Докучаева РАСХН, 2008. - 165 с.
России, в зарубежных странах достаточно широко применяются дифференцированные пороговые значения. Соответственно, результаты проведенной в статье оценки загрязненности почв промышленной территории относительно российских и зарубежных допустимых значений значительно отличаются.

Множество способов оценки экологического состояния почв, предлагаемое, в том числе, и отечественными авторами, свидетельствует о несовершенстве регламентированных нормативно-технической документацией методов. В связи с чем наиболее целесообразным представляется актуализация нормативных требований Российской Федерации с учетом отечественного и зарубежного опыта оценки загрязненности почв. Для оценки почв промышленных территорий в России можно рекомендовать нормативы содержания химических элементов в почвах промышленных и коммерческих территорий, разработанные в Канаде.

Работа выполнена при финансовой поддержке РФФИ в рамках научного проекта № 19-05-50071 и Министерства науки и высшего образования проект № 2019-0858.

12. Водяницкий Ю.Н. Оценка суммарной токсикологической загрязненности почв тяжелыми металлами и металлоидами // Агрохимия. - 2017. - № 2. - С. 56-63.

13. Обзор подходов к оценке экологического состояния и нормированию качества почв / А.Г. Коновалов, Д.В. Рисник, А.П. Левич, П.В Фурсова // Междисциплинарный научный и прикладной журнал «Биосфера». - 2017. - Т. 9. - № 3. C. 214-229. DOI: 10.24855/BIOSFERA.V9I3.371

14. Семенков И., Королева Т. Мировой опыт нормирования содержания химических элементов в почве // Экология и промышленность России. - 2019. - Т. 23. - № 2. - C. 62-67. URL: https://doi.org/10.18412/1816-0395-2019-2-62-67 (дата обращения 01.09.2020)

15. Семенков И.Н., Королева Т.В. Международные системы нормирования содержания химических элементов в почвах: принципы и методы (обзор) // Почвоведение. - 2019. - № 10. С. 1259-1268. DOI: 10.1134/S0032180X19100101

16. Нормативы содержания химических элементов в почве: международный опыт и использование для Западной Сибири / И.Н. Семенков, Т.В. Королева, А.В. Шарапова, Е.В. Терская // География и природные ресурсы. - 2020. - № 1. - С. 41-49. DOI: 10.21782/GIPR0206-1619-2020-1(41-49)

17. Меньшикова Е.А., Караваева Т.И. Особенности оценки состояния грунтов в практике инженерно-экологических изысканий // Инженерные изыскания. - 2019. - № 4. - C. 16-23. URL: https://doi.org/10.25296/1997-8650-2019-13-4-16-23 (дата обращения 01.09.2020).

18. Никитина А.В., Жаткина Т.С., Курбатова А.И. Некоторые аспекты нормирования загрязняющих веществ в почве // Вестник РУДН, серия Экология и безопасность жизнедеятельности. - 2013. - № 5. - С. 84-89.

19. Подлипский И.И. Эколого-геологическая оценка парагенетических геохимических ассоциаций функциональных $30 \mathrm{H}$ Санкт-Петербурга // Инженерные изыскания. - 2013. - № 12. C. 53-59.

20. Трофимов В.Т., Харькина М.А. Еще раз о содержании инженерно-экологических изысканий - достижения, упущенные возможности и недостатки в СП 47.13330.2012 // Инженерные изыскания. - 2015. - № 7. - С. 16-22.

21. Хаустов А.П., Редина М.М. Углеводородное загрязнение почв и грунтов: практика нормирования, проблемы и тенденции // Геоэкология.- 2017. - № 1. - С. 3-14.

22. Topcuoğlu B. Assessment of heavy metal pollution in greenhouse soils // Proceedings of the International Conference on Chemical, 
Environment and Biological Sciences. - Kuala Lumpur, Malaysia, 2014. - P. 164-168

23. Chiroma T.M., Ebewele R.O., Hymore F.K. Comparative assessment of heavy metal levels in soil, vegetables and urban grey waste water used for irrigation in Yola and Kano // International Refereed Journal of Engineering and Science. 2014. - V. 3. - Iss. 2. - P. 1-9.

24. Состояние и охрана окружающей среды муниципального образования «Город Березники» в 2018 г. - Пермь: Изд-во Миг, 2019. - 59 с.

25. Еремченко О.З. Почвы и техногенные поверхностные образования урбанизированных территорий Пермского Прикамья. Пермь: Изд-во Перм. гос. нац. исслед. ун-т, 2016. - 252 с.

26. Guan Y., Shao C., Ju M. Heavy metal contamination assessment and partition for industrial and mining gathering areas // International Journal of Environmental Research and Public Health. - 2014. № 11. - P. 7286-7303.

27. Kamunda C., Mathuthu M., Madhuku M. Health risk assessment of heavy metals in soils from Witwatersrand gold mining basin, South Africa // International Journal of Environmental Research and Public Health. - 2016. - № 13:663. DOI: 10.3390/ijerph13070663

28. Speciation, sources, and risk assessment of heavy metals in suburban vegetable garden soil in Xianyang City, Northwest China / L. Wang, W. Tao, R.C. Smardon et al. // Frontiers of Earth Science. - 2018. - № 12. - P. 397-407. URL: https://doi.org/ 10.1007/s11707-017-0658-8 (дата обращения: 01.09.2020).

29. Assessment of heavy metal contamination levels of street dust in the city of Lublin, Poland / W. Zgłobicki, M. Telecka, S. Skupiński et al.//Environmental Earth Science. - 2018. 77:774. URL: https://doi.org/10.1007/s12665-018-7969-2 (дата обращения: 01.09.2020)

30. Zgłobicki W., Telecka M., Skupiński S. Assessment of short-term changes in street dust pollution with heavy metals in Lublin (E Poland) - levels, sources and risks // Environmental Science Pollution Research. - 2019. - Res. 26. - P. 35049-35060. URL: https://doi.org/ 10.1007/s11356-019-06496-х (дата обращения: 01.09.2020).

31. Weissmannová H.D., Pavlovský J. Indices of soil contamination by heavy metals - methodology of calculation for pollution assessment (minireview) // Environmental Monitoring and Assessment. - 2017. - 189:616. URL: https://doi.org/10.1007/ s10661-017-6340-5 (дата обращения: 01.09.2020).

32. Heavy metal contamination and ecological risk assessment in soils and sediments of an industrial area in Southwestern Nigeria T.O. Kolawole, A.S. Olatunji, M.T. Jimoh, O.T. Fajemila // Journal of Health and Pollution. - 2018. - V. 8. - № 19:180906. URL: https://doi.org/10.5696/2156-9614-8.19.180906 (дата обращения: 01.09.2020).

33. Comparison of heavy metals contamination and ecological risk between soils enriched with compost and chemical fertilizers in the North of Iran and ecological risk assessment / A. Amouei, H. Fallah, H. Asgharnia, A. Mousapour, H. Parsian, M. Hajiahmadi et al. // Environmental Health Engineering and Management Journal. - 2020. - № 7 (1). - P. 7-14URL: http://ehemj. com/article-1-565-en.html (дата обращения: 01.09.2020).

34. Contamination and health risk assessment of heavy metals in the soil of major cities in mongolia / S. Chonokhuu, C. Batbold, B. Chuluunpurev, E. Battsengel, B. Dorjsuren, B. Byambaa // International Journal of Environmental Research and Public Health. - 2019. - 16:2552. URL: https://pubmed.ncbi.nlm.nih. gov/31319540/ (дата обращения 01.09.2020).

35. Spatial distribution of heavy metals and the environmental quality of soil in the Northern Plateau of Spain by geostatistical methods /
F. Santos-Francés, A. Martínez-Graña, C.Á. Zarza, A.G. Sánchez, P.A. Rojo // International Journal of Environmental Research and Public Health. - 2017. - 14:568. URL: https://doi.org/ 10.3390/ijerph14060568 (дата обращения 01.09.2020).

36. CCME. Canadian Council for Ministers for the Environment. 2018 Canadian Environmental Quality Guidelines. URL: http://stts.ccme.ca/en/index.html (дата обращения 01.09.2020).

37. BBodSchV. Bundes-Bodenschutz-und Altlastenverordnung (BBodSchV) vom 12. Juli 1999. Bundesgesetzblatt I, 1554. 33 p. URL: https://www.gesetze-im-internet.de/bbodschv/BBodSchV.pdf (дата обращения 02.09.2020).

38. Australian and New Zeeland Guidelines for the Assessment and Management of Contaminated Sites. 1992. URL: https://www. der.wa.gov.au/images/documents/your-environment/contaminatedsites/guidelines/Assessment_and_management_of_contaminated_s ites.pdf (дата обращения 01.09.2020).

39. Department of Environment and Conservation. Assessment levels for Soil, Sediment and Water. 2010. 56 p. URL: https://www.der. wa.gov.au/images/documents/your-environment/contaminatedsites/guidelines/2009641_-_assessment_levels_for_soil_sediment_ and_water_-_web.pdf (дата обращения 01.09. 2020).

40. Government notice. National norms and standards for the remediation of contaminated land and soil quality. Department of Environmental affairs. National Environmental management: Waste Act. Act no. 59 of 2008 // Governmente Gazette Staatskoerant. - 2014. - V. 587. - № 37603. - 8 p.

41. Inengite A.K., Abasi C.Y., Walter C. Application of pollution indices for the assessment of heavy metal pollution in flood impacted soil // International Research Journal of Pure and Applied Chemistry. - 2015. - V. 8 (3). - P. 175-189. URL: https://doi.org/10.9734/IRJPAC/2015/17859 (дата обращения: 01.09.2020)

42. Muller G. Index of geo-accumulation in sediments of the Rhine River // GeoJournal. - 1969. - № 2. - P. 108-118.

43. Overview on current criteria for heavy metals and its hint for the revision of soil environmental quality standards in China / Chen Shi-bao, Wang Meng, Li Shan-shan, Zhao Zhong-qiu, E Wen-di // Journal of Integrative Agriculture. - 2018. - № 17 (4). - P. 765 774. DOI: $10.1016 / \mathrm{S} 2095-3119(17) 61892-6$

44. Hakanson L. An ecological risk index for aquatic pollution control. A sedimentological approach // Water Research. - 1980. № 14 (8). - P. 975-1001. URL: https://doi.org/10.1016/00431354(80)90143-8 (дата обращения: 01.09.2020).

45. Calculation of heavy metals' toxicity coefficient in the evaluation of potential ecological risk index / Z. Xu, S. Ni, X. Tuo, C. Zhang // Environmental Science and Technology. - 2008. - № 31. - P. 112-115.

46. Pollution indices as useful tools for the comprehensive evaluation of the degree of soil contamination - a review / J.B. Kowalska, R. Mazurek, M. Gasiorek et al. // Environmental Geochemestry and Health. - 2018. - № 40. - P. 2395-2420. URL: https://doi.org/ 10.1007/s10653-018-0106-z(0 (дата обращения: 01.09.2020).

47. Soil pollution indices conditioned by medieval metallurgical activity - a case study from Krakow (Poland) / J. Kowalska, R. Mazurek, M. Gasiorek, M. Setlak, T. Zaleski, J. Waroszewski // Environmental Pollution. - 2016. - № 218. - P. 1023-1036. URL: https://doi.org/10.1016/j.envpol.2016.08.053 (дата обращения: 01.09.2020).

48. Геохимия окружающей среды / Ю.Е. Сает, Б.А. Ревич, Е.П. Янин и др. - М.: Изд-во Недра, 1990. - 335 с.

Поступила 08.09.2020 г.

\section{Информация об авторах}

Ушакова E.C., младший научный сотрудник лаборатории биогеохимии техногенных ландшафтов Естественнонаучного института Пермского государственного национального исследовательского университета.

Караваева Т.И., кандидат геолого-минералогических наук, старший научный сотрудник лаборатории экологической геологии Естественнонаучного института Пермского государственного национального исследовательского университета.

Белкин П.А., кандидат геолого-минералогических наук, научный сотрудник лаборатории экологической геологии Естественнонаучного института Пермского государственного национального исследовательского университета. 
UDC 504.054

\title{
ECOLOGICAL CONDITION OF SOILS IN INDUSTRIAL AREAS (AS IN THE CASE OF BEREZNIKI, PERM REGION): COMPARISON OF RUSSIAN AND FOREIGN METHODS OF ASSESSMENT
}

\author{
Evgenia S. Ushakova ${ }^{1}$, \\ ushakova.evgeniya@gmail.com
}

Tatiana I. Karavaeva ${ }^{1}$, jewel_@list.ru

Pavel A. Belkin 1 pashabelkin@mail.ru

1 Perm State National Research University,

4, Genkel street, Perm, 614990, Russia.

The relevance. Intensive anthropogenic impact on the environment, specifically within industrial areas, contributes to soil degradation and accumulation of technophilic chemical elements in the soil cover. The increasing contamination of urban soils with heavy metals due to intense industrial load is a serious environmental problem. Despite the increased interest in ecological condition of soils in industrial areas, the current standardization system in the Russian Federation is not sufficiently developed and precludes an accurate specification of contamination.

The main aim of the research is to determine the level of soil contamination with heavy metals within the industrial area of an urban territory, compare Russian and foreign methods for soil contamination assessment and justification of the need for updating reference documentation.

Methods. The content of heavy metals in soils was determined by the mass spectrometry method on the basis of the nanomineralogy Sector of the center for Collective Use of Perm State National Research University.

Results and conclusions. Russian and foreign methods for assessing ecological condition of soils are considered. The level of soil contamination by heavy metals and metalloids within the industrial areas of large chemical enterprises of Perm region was estimated using Russian and foreign soil quality standards, total pollution indices and potential ecological risk. The relevance of functional purpose of territories when assessing pollution using individual indices is shown. Similar results were obtained for assessing the degree of soil pollution when using Russian total indices, not regulated by reference documentation, and foreign total indices. It is deduced that it is necessary to update the regulatory requirements of the Russian Federation, taking into account Russian and foreign experience in assessing soil contamination.

Key words:

Soil quality guidelines, heavy metals, soil contamination level, industrial areas, total pollution indices, potential ecological risk.

The research was financially supported by the RFBR within the science project no. 19-05-50071 and the Ministry of Science and Higher Education, project no. 2019-0858.

\section{REFERENCES}

1. Kasimov N.S., Vlasov D.V. Heavy metals and metalloids in urban soils of Russian cities (according to the annual reports of Rosgidromet). Vestnik Moskovskogo universiteta. Seriya 5, Geografiya, 2018, no. 3, pp. 14-22. In Rus.

2. Vlasov D.V., Kasimov N.S. Geochemical anomalies of metals and metalloids in landscape components of the eastern part of Moscow: parageneses of chemical elements and typology. Vestnik Moskovskogo universiteta. Seriya 5, Geografiya, 2016, no. 3, pp. 50-57. In Rus.

3. Voronchikhina E.A., Ushakova E.S. Geokhimiya landshaftov [Geochemistry of landscapes]. Perm, Perm State National Research University Publ., 2012. 139 p.

4. Korlyakov I., Kasimov N., Kosheleva N. Heavy metals and metalloids in the soil cover of the city of Ulan-Ude. PNRPU. Applied Ecology. Urban Development, 2019, no. 3. pp. 120-137. In Rus. DOI: $10.15593 / 2409-5125 / 2019.03 .09$.

5. Doležalová Weissmannová $\mathrm{H}$., Mihočová S., Chovanec P., Pavlovský J. Potential Ecological Risk and Human Health Risk Assessment of Heavy Metal Pollution in Industrial Affected Soils by Coal Mining and Metallurgy in Ostrava, Czech Republic. International Journal of Environmental Research and Public Health 2019, 16, 4495. DOI: 10.3390/ijerph16224495

6. Yaylal-Abanuz G. Heavy metal contamination of surface soil around Gebze industrial area, Turkey. Microchemical Journal, 2011, vol. 99, pp. 82-92. Available at: https://doi.org/ 10.1016/j.microc.2011.04.004 (accessed: 1 September 2020).
7. Gorlushkin K.S., Badmaeva S.E. Content of heavy metals in soils of industrial enterprises in Krasnoyarsk. Vestnik KrasGAU, 2018, no. 6, pp. 254-258. In Rus.

8. Radomskaya V.I., Borodina N.A. Assessment of anthropogenic contamination in an urban territory by the example of Blagoveshchensk city. Geoecology. Engineering geology. Hydrogeology. Geokryology, 2019, no. 6, pp. 79-93. DOI: 10.31857/S086978092019679-93 In Rus.

9. Shishkina D.Yu. Tyazhelye metally v pochvakh Rostova-na-Donu [Heavy metals in soils of Rostov-on-Don]. Taganrog, Southern Federal University Publ. house, 2017. 98 p.

10. Dabakhov M.V. Ekologicheskaya otsenka tekhnogenno zagryaznennykh pochv urbanizirovannykh territoriy $i$ promyshlennykh zon g. Nizhnego Novgoroda. Avtoreferat Dis. Kand. nauk [Ecological assessment of the technogenic polluted soils of the urbanized territories and industrial zones of Nizhny Novgorod. Cand. Diss. Abstract]. Moscow, 2012. $46 \mathrm{p}$

11. Vodianitsky Yu.N. Tyazhelye metally $i$ metalloidy $v$ pochvakh [Heavy metals and metalloids in soils]. Moscow, GNU Soil Institute named after V.V. Dokuchayeva RAASHN, 2008. 165 p.

12. Vodianitskiy Yu.N. Assessment of the total toxicological pollution of the soil with heavy metals and metalloids. Agrochemistry, 2017, no. 2, pp. 56-63. In Rus.

13. Konovalov A.G., Risnik D.V., Levich A.P., Fursova P.V. Overview of approaches to the ecological state estimation and soil quality regulation. Interdisciplinary scientific and applied journal «Biosphere», 2017, vol. 9, no. 3, pp. 214-229. In Rus. DOI: 10.24855/BIOSFERA.V9I3.371. 
14. Semenkov I.N., Korolyeva T.V. World experience in rationing the content of chemical elements in the soil. Ecology and Industry of Russia, 2019; vol. 23, no. 2, pp. 62-67. In Rus. Available at: doi.org/10.18412/1816-0395-2019-2-62-67 (accessed: 1 September 2020).

15. Semenkov I.N., Korolev T.V. International systems of the chemical elements content rationing in soils: principles and methods (review). Soil science, 2019, no. 10, pp. 1259-1268. In Rus. DOI: 10.1134/S0032180X1910010116.

16. Semenkov I.N., Korolev T.V., Sharapova A.V., Terskaya E.V. Standards for the content of chemical elements in soil: international experience and use for Western Siberia. Geography and natural resources, 2020, no. 1, pp. 41-49. In Rus. DOI: 10.21782/GIPR0206-1619-2020-1(41-49).

17. Menshikova E.A., Karavaeva T.I. Estimation features of soil conditions in practice of engineering and ecological surveys. Engineering Surveys, 2019, vol. XIII, no. 4, pp. 16-23. In Rus. Available at: https://doi.org/10.25296/1997-8650-2019-13-4-16-23.18 (accessed: 1 September 2020)

18. Nikitina A.V., Zhatkina T.S., Kurbatova A.I., Some aspects of pollutants rationing in soil. PFUR Newsletter, Ecology and life safety series, 2013, no. 5, pp. 84-89. In Rus.

19. Podlipsky I.I. Ecological and geological assessment of paragenetic geochemical associations of functional zones of Saint-Petersburg. Engineering Investigations, 2013, no. 12, pp. 53-59. In Rus.

20. Trofimov V.T., Kharkina M.A. Once again about the content of engineering and ecological surveys - achievements, missed opportunities and shortcomings in SP 47.13330.2012. Engineering surveys, 2015, no. 7, pp. 16-22. In Rus.

21. Khaustov A.P., Redina M.M. Hydrocarbon pollution of soils and grounds: practice of normalization, problems and tendencies. Geoecology, 2017, no. 1, pp. 3-14. In Rus.

22. Topcuoğlu B. Assessment of heavy metal pollution in greenhouse soils. Proceedings of the International Conference on Chemical, Environment and Biological Sciences (CEBS-2014). Kuala Lumpur, Malaysia, 2014. pp. 164-168.

23. Chiroma T.M., Ebewele R.O., Hymore F.K. Comparative assessment of heavy metal levels in soil, vegetables and urban grey waste water used for irrigation in Yola and Kano. International Refereed Journal of Engineering and Science (IRJES), 2014, vol. 3 , Iss. 2, pp. 1-9.

24. Sostoyanie i okhrana okruzhayushchey sredy munitipalnogo obrazovaniya «Gorod Berezniki» v 2018 g. [Report of State and Environmental protection of the Municipality «City of Berezniki» 2018 year]. Perm, Mig Publ., 2019. 59 p

25. Eremchenko O.Z. Pochvy i tekhnogennye poverkhnostnye obrazovaniya urbanizirovannykh territoriy Permskogo Prikamya [Soils and technogenic formations of urbanized territories of the Perm region]. Perm, Perm State National Research University Publ., 2016. $252 \mathrm{p}$.

26. Guan Y., Shao C., Ju M. Heavy metal contamination assessment and partition for industrial and mining gathering areas. International Journal of Environmental Research and Public Health, 2014, vol. 11, pp. 7286-7303. Available at: https://www.ncbi nlm.nih.gov/pmc/articles/PMC4113876/ (accessed 1 September 2020)

27. Kamunda C., Mathuthu M., Madhuku M. Health risk assessment of heavy metals in soils from Witwatersrand Gold Mining Basin, South Africa. International Journal of Environmental Research and Public Health, 2016, no. 13:663. Available at: https://doi.org/10.3390/ijerph13070663 (accessed 1 September 2020).

28. Wang L., Tao W., Smardon R.C. Speciation, sources, and risk assessment of heavy metals in suburban vegetable garden soil in Xianyang City, Northwest China. Frontiers of Earth Science, 2018 vol. 12, pp. 397-407. Available at: https://doi.org/10.1007/s11707017-0658-8 (accessed 1 September 2020).

29. Zgłobicki W., Telecka M., Skupiński S. Assessment of heavy metal contamination levels of street dust in the city of Lublin, Poland. Environmental Earth Science, 2018, 77:774. Available at: https://doi.org/10.1007/s12665-018-7969-2 (accessed 1 September 2020).

30. Zgłobicki W., Telecka M., Skupiński S. Assessment of short-term changes in street dust pollution with heavy metals in Lublin (E Poland) - levels, sources and risks. Environmental Science Pollution
Research, 2019, Res. 26, pp. 35049-35060. Available at: https://doi.org/10.1007/s11356-019-06496-x (accessed 1 September 2020).

31. Weissmannová H.D., Pavlovský J. Indices of soil contamination by heavy metals - methodology of calculation for pollution assessment (minireview). Environmental Monitoring and Assessment, 2017, 189:616. Available at: https://doi.org/10.1007/s10661017-6340-5 (accessed 1 September 2020).

32. Kolawole T.O., Olatunji A.S., Jimoh M.T., Fajemila O.T. Heavy metal contamination and ecological risk assessment in soils and sediments of an industrial area in Southwestern Nigeria. Journal of Health and Pollution, 2018, vol. 8, no. 19:180906. Available at: https://doi.org/10.5696/2156-9614-8.19.180906 (accessed 1 September 2020).

33. Amouei A., Fallah H., Asgharnia H., Mousapour A., Parsian H., Hajiahmadi M. Comparison of heavy metals contamination and ecological risk between soils enriched with compost and chemical fertilizers in the North of Iran and ecological risk assessment. Environmental Health Engineering and Management Journal, 2020, no. 7 (1), pp. 7-14. Available at: http://ehemj.com/ article-1-565en.html (accessed 1 September 2020).

34. Chonokhuu S., Batbold C., Chuluunpurev B., Battsengel E., Dorjsuren B., Byambaa B. Contamination and health risk assessment of heavy metals in the soil of major cities in Mongolia. International Journal of Environmental Research and Public Health, 2019, 16:2552. Available at: https://pubmed.ncbi.nlm.nih.gov/ 31319540/ (accessed 1 September 2020).

35. Santos-Francés F., Martínez-Graña A., Zarza C.Á., Sánchez A.G., Rojo P.A. Spatial distribution of heavy metals and the environmental quality of soil in the Northern Plateau of Spain by geostatistical methods. International Journal of Environmental Research and Public Health, 2017, 14:568. Available at: https://doi.org/10.3390/ijerph14060568 (accessed 1 September 2020).

36. CCME. Canadian Council for Ministers for the Environment. 2018 Canadian Environmental Quality Guidelines. Available at: http://st-ts.ccme.ca/en/index.html (accessed 1 September 2020).

37. BBodSchV. Bundes-Bodenschutz-und Altlastenverordnung (BBodSchV) vom 12. Juli 1999. Bundesgesetzblatt I, 1554. 33 p. Available at: https://www.gesetze-im-internet.de/bbodschv/ BBodSchV.pdf (accessed 2 September 2020).

38. Australian and New Zeeland Guidelines for the Assessment and Management of Contaminated Sites. 1992. Available at: https://www.der.wa.gov.au/images/documents/your-environment/ contaminated-sites/guidelines/Assessment_and_management_of_ contaminated_sites.pdf (accessed 1 September 2020).

39. Department of Environment and Conservation. Assessment levels for Soil, Sediment and Water. 2010. 56 p. Available at: https://www.der.wa.gov.au/images/documents/your-environment/ contaminated-sites/guidelines/2009641__assessment_levels_for soil_sediment_and_water_-_web.pdf (accessed 1 September 2020).

40. Government notice. National norms and standards for the remediation of contaminated land and soil quality. Department of Environmental affairs. National Environmental management: Waste Act. Act no. 59 of 2008. Governmente Gazette Staatskoerant, 2014, vol. 587, no. 37603, 8 p. Available at: https://cer.org.za/wpcontent/uploads/2010/03/national-environmental-managementwaste-act-59-2008-national-norms-and-standards-for-theremediation-of-contaminated-land-and-soil-quality_20140502GGN-37603-00331.pdf (accessed 1 September 2020).

41. Inengite A.K., Abasi C.Y., Walter C. Application of pollution indices for the assessment of heavy metal pollution in flood impacted soil. International Research Journal of Pure and Applied Chemistry, 2015, vol. 8 (3), pp. 175-189. Available at: https://doi.org/10.9734/IRJPAC/2015/17859 (accessed 1 September 2020)

42. Muller G. Index of Geo-Accumulation in Sediments of the Rhine River. GeoJournal, 1969, vol. 2, pp.108-118.

43. Chen Shi-bao, Wang Meng, Li Shan-shan, Zhao Zhong-qiu, E Wen-di. Overview on current criteria for heavy metals and its hint for the revision of soil environmental quality standards in China. Journal of Integrative Agriculture, 2018, vol. 17 (4), pp. 765-774. DOI: 10.1016/S2095-3119(17)61892-6 Available at: http://www.chinaagrisci.com/Jwk_zgnykxen/EN/10.1016/S20953119(17)61892-6 (accessed 1 September 2020). 
44. Hakanson L. An ecological risk index for aquatic pollution control A sedimentological approach. Water Research, 1980, vol. 14 (8), pp. 975-1001. Available at: https://doi.org/10.1016/00431354(80)90143-8 (accessed 1 September 2020).

45. Xu Z., Ni S., Tuo X., Zhang C. Calculation of heavy metals' toxicity coefficient in the evaluation of potential ecological risk index. Environmental Science and Technology, 2008, no. 31, pp. 112-115. Available at: https://en.cnki.com.cn/Article_en/ CJFDTOTALFJKS200802029.htm (accessed 1 September 2020).

46. Kowalska J.B., Mazurek R., Gasiorek M. Pollution indices as useful tools for the comprehensive evaluation of the degree of soil contamination - a review. Environmental Geochemestry and
Health, 2018, 40:2395-2420. Available at: https://doi.org/ 10.1007/s10653-018-0106-z(0 (accessed 1 September 2020).

47. Kowalska J., Mazurek R., Gąsiorek M., Setlak M., Zaleski T.,

Waroszewski J. Soil pollution indices conditioned by medieval metallurgical activity - a case study from Krakow (Poland). Environmental Pollution, 2016, no. 218, pp. 1023-1036. Available at: https://doi.org/10.1016/j.envpol.2016.08.053.123 (accessed 1 September 2020).

48. Saet Yu.E., Revich B.A., Yanin E.P. Geokhimiya okruzhayushchey sredy [Environmental geochemistry]. Moscow, Nedra Publ., 1990. $335 \mathrm{p}$.

Received: 8 September 2020.

\section{Information about the authors}

Evgenia S. Ushakova, junior researcher, Perm State National Research University.

Tatiana I. Karavaeva, Cand. Sc., senior researcher, Perm State National Research University.

Pavel A. Belkin, Cand. Sc., researcher, Perm State National Research University. 